\title{
SISTEM INFORMASI PENILAIAN KARAKTER SISWA BERBASIS WEB DENGAN METODE SAW
}

\author{
Muhammad Fadh Abdurrahman, Abdi Pandu Kusuma \\ Program Studi Teknik Informatika, FTI Universitas Islam Balitar, Blitar \\ Jalan Majapahit No 2-4 Sananwetan, Kecamatan Sananwetan, Kota Blitar \\ madurra16@gmail.com
}

\begin{abstract}
ABSTRAK
Lembaga pendidikan di SMP Islam Anharul Ulum dalam mengelola dan menyimpan data nilai akhir masih menggunakan metode manual atau tulisan di buku arsip. Penyampaian nilai dari hasil belajar dan evaluasi siswa dilakukan pada setiap akhir semester menggunakan buku rapor, sehingga dapat menyebabkan penyampaian informasi penilaian siswa kepada orang tua menjadi terlambat dan akan berdampak pada kualitas pendidikan karakter siswa. Tujuan pembuatan sistem informasi penilaian karakter siswa agar mempermudah pihak sekolah dalam mengelola data perilaku keseharian siswa dan evaluasi belajar siswa di linkungan sekolah dengan menentukan nilai akhir secara akurat sehingga orang tua siswa mengetahui perkembangan karakter siswa. Dalam menentukan nilai akhir yang akurat maka diperlukan suatu sistem untuk mendukung keputusan penilaian karakter siswa menggunakan metode SAW (Simple Additive Weighting), yang dikenal sebagai metode perhitungan atau penjumlahan terbobot. Penggunaan metode SAW pada sistem penilaian karakter siswa, mampu menghitung dan merangking nilai akhir berdasarkan rumusnya. Pembangunan sistem ini menggunakan bahasa pemrograman PHP dengan database MySQL serta memiliki hasil pengujian fungsionalitas sebesar 93,86\% dengan alpha testing dan 77,68\% dengan beta testing. Hasil pengujian metode SAW, terdapat selisih 0,01 antara perhitungan manual dengan perhitungan aplikasi. Selisih itu dikatakan valid atau normal karena perhitungan manual nilainya belum dibulatkan, sedangkan perhitungan aplikasi nilainya sudah dibulatkan.
\end{abstract}

\section{Kata kunci: Simple additive weighting, Penilaian karakter, Sistem informasi}

\section{PENDAHULUAN}

Perkembangan teknologi informasi dari tahun ke tahun bekembang sangat cepat dalam segala bidang. Teknologi informasi dapat dipahami secara umum sebagai pengelolaan informasi yang mengarah pada teknologi komputer yang saling terkoneksi untuk menyampaiakan sebuah informasi kepada kalayak umum (Supriyanto, 2005:5). Perkembangan teknologi membuat berbagai masalah yang ada di instansi perusahaan, pemerintah maupun di instansi sekolah terutama di bidang pendidikan dapat dipermudah dalam penyelesaianya.

Hasil dari observasi yang dilakukan di SMP Islam Anharul Ulum, setiap akhir semester dilakukan dokumentasi penilaian akhir untuk mengetahui tingkat kemampuan belajar siswa, serta penilaian absensi siswa dalam mengikuti pembelajaran di kelas guna meningkatkan kedisiplinan siswa. Wali kelas akan menerima nilai tugas-tugas dan nilai ujian akhir semester dari berbagai mata pelajaran yang akan di kelola untuk menentukan nilai karakter siswa.

Dari beberapa masalah yang muncul maka diperlukan solusi yang mempermudah dalam penyampaian informasi atau penyampaian laporan akademik maupun perilaku siswa dengan cara membuat sistem informasi penilaian karakter siswa secara terintegrasi di SMP Islam Anharul Ulum untuk menciptakan karakter siswa yang baik dan berbudi pekerti yang luhur dengan adanya sistem informasi suatu data dapat disimpan dengan baik dan tersetruktur, sehingga dapat dengan mudah dan cepat dalam mengakses suatu informasi (Didik, Haryanto, 2008:2).

Sistem informasi penilaian karakter siswa berbasis web dengan metode SAW dapat dimanfaatkan sebagai pengganti sistem penilaian karakter siswa secara manual menuju sistem yang terkomputerisasi. Penggunaan metode SAW dalam sistem ini untuk merangking nilai karakter siswa yang nilainya diambil dari perhitungan nilai kriteriakriteria yang telah ada di sekolah tersebut. Hal tersebut membuat para orang tua siswa tahu tentang seberapa besar nilai karakter siswa dalam lingkungan sekolah. Nilai tersebut akan digunakan guru dan wali murid sebagai pembanding antara semester terdahulu dengan semester yang sekarang, apakah pendidikan karakter siswanya meningkat atau tidak. Sistem ini dibuat dengan menggunakan bahasa pemrogaman PHP dan MySQL sebagai database server yang akan di uji fungsionalitas dan kelayakan sistemnya agar dapat digunakan secara efektif dan efisien di SMP Islam Anharul Ulum.

Pengertian sistem informasi adalah sistem yang menyediakan sebuah informasi dengan cara sedemikian rupa yang bermanfaat sebagai penyampaian suatu informasi bagi penerimanya., sistem informasi juga dapat diartikan sebagai seperangkat entitas yang terdiri dari hardaware, software dan brainware yang saling bekerjasama untuk menyediakan data informasi yang berguna bagi penerima atau kalayak umum (Herlina \& Rasyid, 2016). 
Aplikasi web adalah suatu jenis aplikasi komputer yang dapat diakses dengan web browser, selama pengguna dapat mengakses web server. Web server adalah server yang melayani permintaan dari aplikasi web yang digunakan oleh pengguna (Abdul Kadir, 2009). website secara umum dapat diartikan sebagai sebuah halaman yang tersedia dalam sebuah server dan diakses menggunakan jaringan internet dimana didalamnya berisi bermacam-macam informasi yang dibutuhkan pengguna dari suatu konten tertentu. Sebuah halaman web yang ditampilkan pada umumnya dibuat dengan serangkaian plain text yang dikenal dengan istilah HTML (Hyper Text Markup Language) atau XHTML (eXtensible HyperText Markup Languange).

Metode SAW (Simple Additive Weighting) Menurut Sri Kusumadewi, Dkk (2006:74) terdapat beberapa model perhitungan dalam membangun Sistem Pendukung Keputusan (SPK), salah satunya adalah metode SAW (Simple Additive Weighting) sering juga dikenal dengan istilah metode perhitungan atau penjumlahan terbobot. Konsep dasar metode SAW (Simple Additive Weighting) adalah mencari perhitungan atau penjumlahan terbobot dan rating kinerja disetiap alternatif dari semua atribut yang telah ditentukan.

Penelitian ini memiliki beberapa sumber referensi penelitian terdahulu meliputi. Penelitian yang dilakukan oleh Hengki dan Maria., (2016), yang berjudul "Aplikasi Sistem Pendukung Keputusan Penentuan Siswa Bermasalah Menggunakan Metode SAW Pada Sekolah SMP Swasta Mulia Pratama Medan". Tujuan dari penelitian ini yaitu aplikasi pendukung keputusan ini memepermudah para guru mengetahui siswa yang bermasalah dalam nilai akademik maupun non akademik. Aplikasi ini dirancang agar dapat mempercepat penentuan siswa yang bermasalah yang kemudian akan diinformasikan kepada guru wali kelas. [1]

Penelitian yang dilakukan oleh Irawan, Susanti dan Triyanto., (2016) dengan judul "Analisa Dan Perancangan Sistem Informasi Sekolah Berbasis Website Untuk Penyampaian Informasi Sekolah Dan Media Promosi Kepada Masyarakat". Di dalam penelitian ini menjelaskan tentang IT yang dapat digunakan Sistem ini digunakan untuk membatu pihak sekolah dalam menyampaikan berbagai informasi kepada guru, karyawan, siswa dan masyarakat umum. Hal ini membuat transparansi informasi sekolah dapat terealisasi dengan cepat dan mudah. [2]

Penelitian serupa juga dilakukan oleh Irma Yunita dan Siti Sopiah., (2019) dengan judul "Perancangan Sistem Informasi Akademik Sekolah Berbasis Website Dengan Laravel 5" membahas tentang Sistem informasi yang berguna untuk mempermudah para guru dalam mengelola administrasi sekolah yang dikususkan dalam penyimpanan data presensi siswa dan kumpulan data siswa ke dalam database. Hal tersebut dilakukan agar para guru memiliki back up data data sebelumnya yang telah disimpan di database. [3]

Berdasarkan penelitian yang dilakukan Ahmad Latif, Muh. Hasbi dan Syawaluddin., (2019), dengan judul "Pengembangan Aplikasi Layanan Akademik Mahasiswa Berbasis Software". Sistem yang dihasilkan dari penelitian ini yaitu Aplikasi layanan akademik berbasis software yang dapat membantu pengguna baik mahasiswa, maupun staf akademik dalam mempermudah mengakses layanan akademik secara cepat. Melalui aplikasi ini staf akademik dapat menyampaikan atau menyuguhkan data informasi dan layanan akademik yang dibutuhkan mahasiswa melalui menu yang disediakan dalam software tersebut. [4]

Penelitian serupa dilakukan oleh Icha Dias dan Herny. (2018) dengan jurnal yang berjudul "Pembobotan Hasil Evaluasi Belajar Murid Menggunakan Metode Simple Additive Weighting". Pada penelitian ini bertujuan untuk membuat Sistem berbasis website yang mempermudah penyampaian informasi dan proses perhitungan nilai sehingga wali murid tetap dapat memonitoring hasil belajar murid kapanpun dan dimanapun dengan mengedepankan efektifitas dan efisiensi data dari segi tenaga, biaya, dan keamanan data, serta dari segi kebutuhan, baik sekarang maupun pengembangan dimasa yang akan datang [5]

\section{METODE PENELITIAN}

Dalam penulisan penelitian ini menggunakan beberapa metodelogi penelitian yang berupa:

\subsection{Metode Pengumpulan Data}

Dalam metode pengumpulan data yang digunakan penulis diantaranya adalah:

1. Pengamatan (Observasi)

Observasi adalah metode pengumpulan data yang dilakukan untuk memperoleh gambaran riil dari peristiwa yang terjadi dengan cara melakukan pengamatan langsung ke objek yang akan diteliti, untuk mendapatkan informasi-informasi yang akurat melalui sumbernya secara langsung kelokasi penelitian.

2. Wawancara (Interview)

Wawancara merupakan teknik pengumpulan data yang dilakukan melalui tatap muka dan tanya jawab langsung antara peneliti terhadap narasumber. Dengan catatan peneliti harus membuat daftar pertanyaan yang akan ditanyakan kepada narasumbernya terlebih dahulu.

\section{ANALISA DAN PERANCANGAN}

\subsection{Flowchart sistem}

Ada dua flowchart yang dibuat dalam merancang sebuah sistem informasi penilaian karakter siswa yaitu, Flowcart Admin, Flowchart User dan Flowchart Metode SAW. Seperti flowchart berikut. 


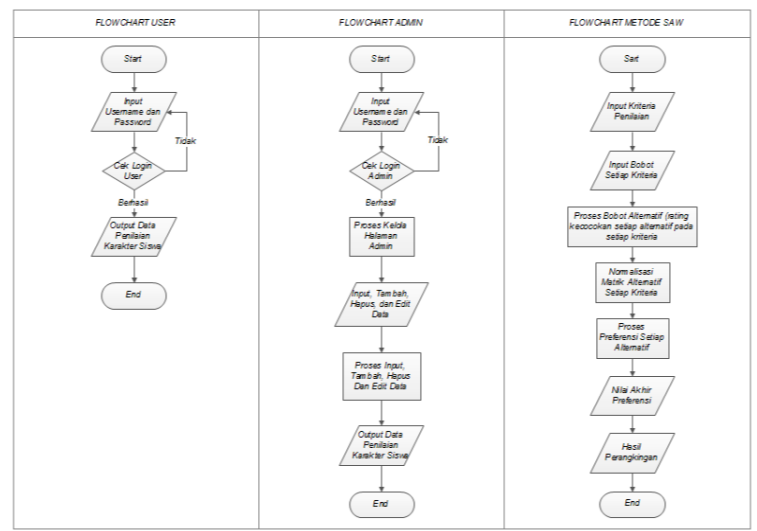

Gambar 1. Flowchart sistem

\subsection{Data Flow Diagram (DFD) Level 0}

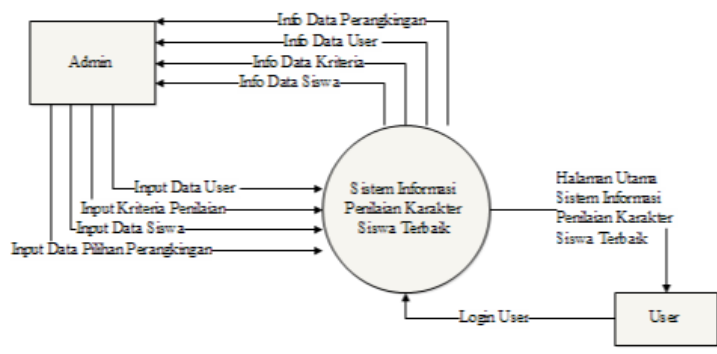

Gambar 2. DFD Level 0

\subsection{Data Flow Diagram (DFD) Level 1}

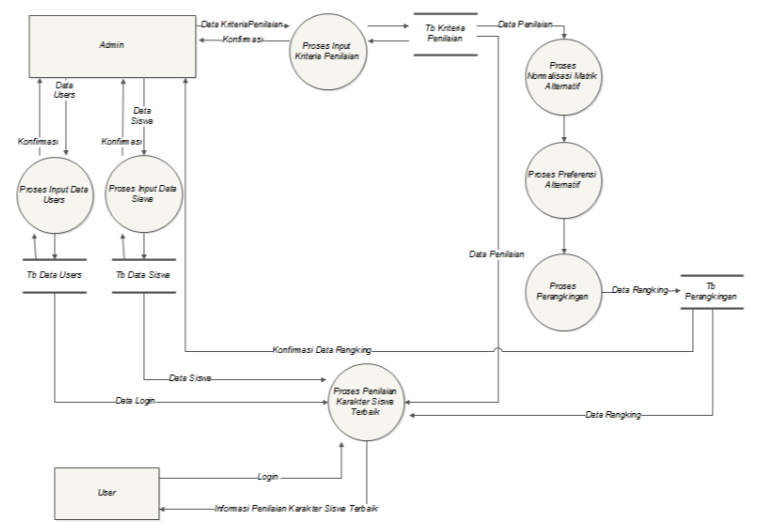

Gambar 3. DFD Level 1

\subsection{Entity Relationship Data (ERD)}

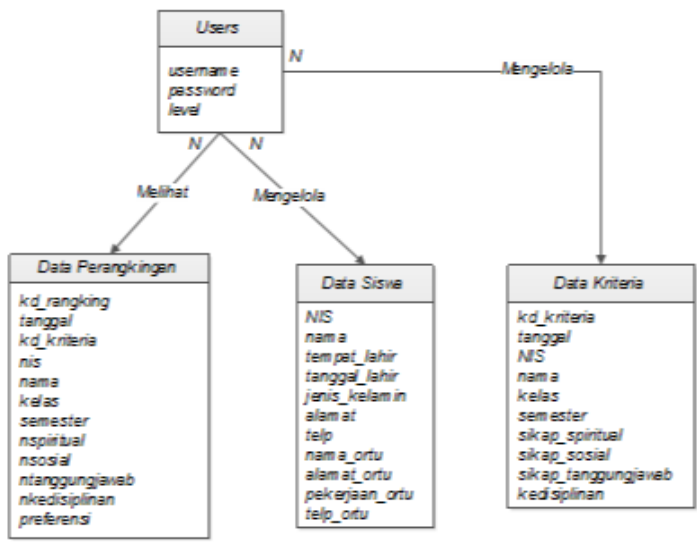

Gambar 4. Entity Relationship Data

\subsection{Metode SAW (Simple Additive Weight)}

Penelitian ini menggunakan perhitungan Algoritma SAW yang langkah pertamanya adalah menentukan nilai kriteria $\mathrm{Cj}$ pada suatu alternatif $\mathrm{Ai}$, bobot preferensi $(\mathrm{Wj})$ setiap kriteria cj. Bobot kriteria ini diambil dari hasil penelitian di SMP Islam Anharul Ulum dengan sebagai berikut:

Tabel 1. Kriteria Dan Bobot Penilaian

\begin{tabular}{|l|c|}
\hline \multicolumn{1}{|c|}{ Kriteria } & Bobot \\
\hline Sikap Spiritual & $35 \%$ \\
\hline Sikap Sosial & $20 \%$ \\
\hline Sikap Tanggung Jawab & $20 \%$ \\
\hline Kedisiplinan & $25 \%$ \\
\hline
\end{tabular}

Pada Standar Nilai Algoritma Metode SAW dijelaskan sebagai standar nilai dari penilaian pihak sekolah dengan range penilaiannya adalah 1 sampai dengan 4, dapat dilihat seperti tabel berikut:

Tabel 2. Range Kriteria Penilaian

\begin{tabular}{|l|c|}
\hline \multicolumn{1}{|c|}{ Keterangan } & Nilai \\
\hline Sangat Baik & 4 \\
\hline Baik & 3 \\
\hline Cukup & 2 \\
\hline Kurang & 1 \\
\hline
\end{tabular}




\section{HASIL DAN PEMBAHASAN}

Dalam impementasi sistem informasi penilaian karaktersiswa terbaik berbasis web memiliki beberapa menu sebagai berikut.

\subsection{Halaman Login}

Tampilan awal atau pertama admin maupun user saat Sistem Informasi Penilaian Karakter Siswa Terbaik di jalankan harus mengisi User Name dan Password yang sesuai dengan ketentuan sistem yang dibuat.

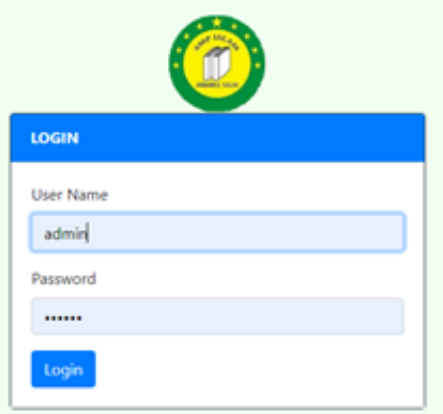

Gambar 5. Halaman Login

\subsection{Halaman Home Admin}

Tampilan ini adalah halaman utama admin yang berisi menu bar SMP Islam Anharul Ulum yang bersifat responsive, seperti gambar berikut.

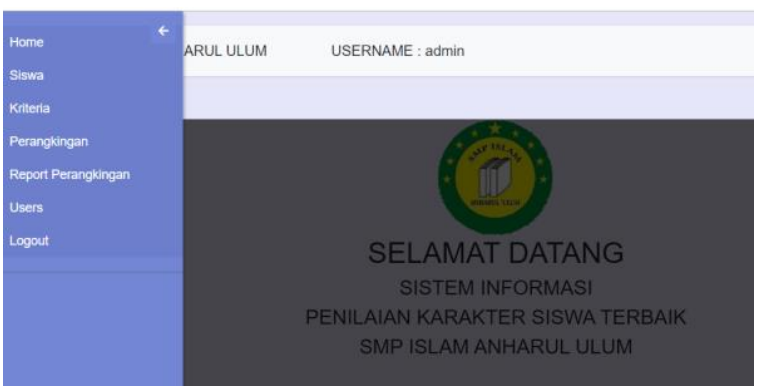

Gambar 6. Halaman Home Admin

\subsection{Halaman Home User}

Tampilan ini adalah halaman utama admin yang berisi menu bar SMP Islam Anharul Ulum yang bersifat responsive, seperti gambar berikut.

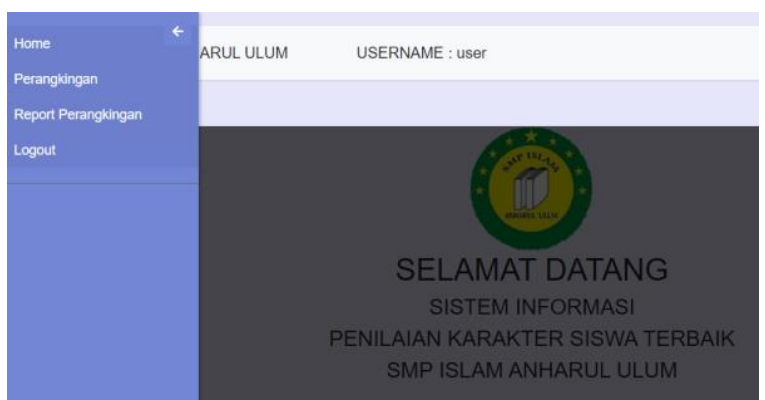

Gambar 7. Halaman Home User

\subsection{Menu Siswa}

Pada menu ini admin dapat melihat data siswa SMP Islam Anharul Ulum yang telah diinputkan. Tampilan ini juga memiliki beberapa tombol fungsional yang yang berupa menu Tambah, kotak Search dan ikon (+) berwarna biru yang memiliki kegunaan untuk Edit maupun Delete Data Siswa.

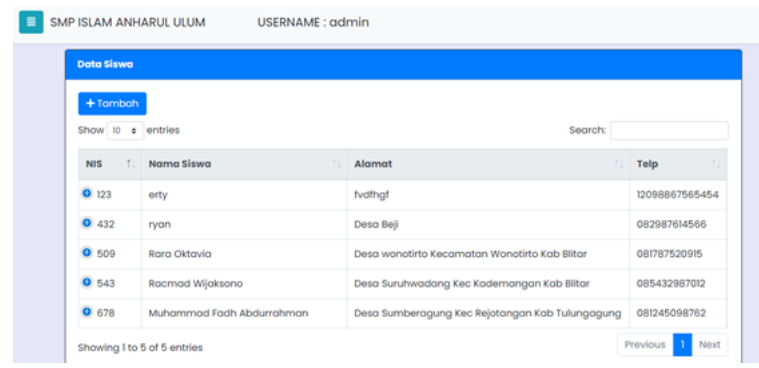

Gambar 8. Halaman Menu Siswa

\subsection{Menu Kriteria}

Pada menu ini akan menampilkan tampilan Data Kriteria untuk admin dan juga dapat menambah, edit, delete data kriteria.

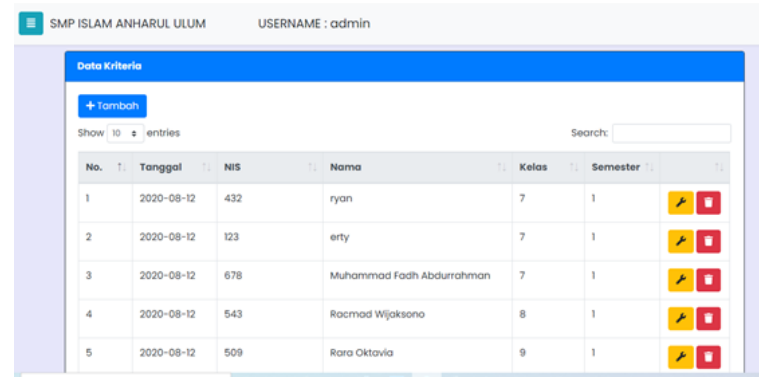

Gambar 9. Halaman Menu Kriteria

\subsection{Menu Perangkingan}

Pada menu ini admin dan user dapat melihat Data Rangking Karakter Siswa dengan cara pilih Kelas, pilih Semester dan klik tombol Proses, maka akan tampil data rangking karakter siswa yang sesuai dengan pilihannya.

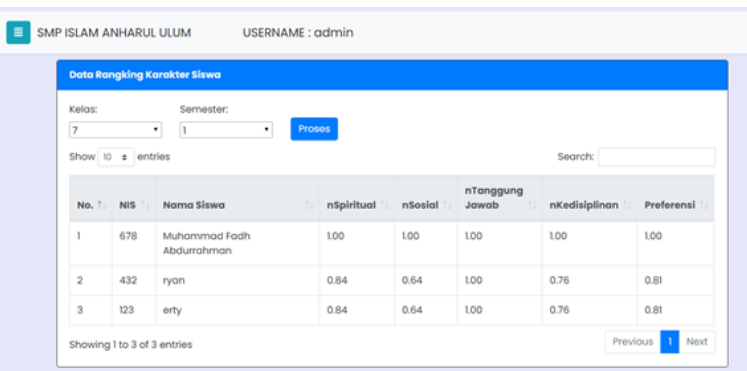

Gambar 10. Halaman Menu Perangkingan 


\subsection{Menu Users}

Menu ini digunakan admin dalam mengelola data users (tambah, edit delete).

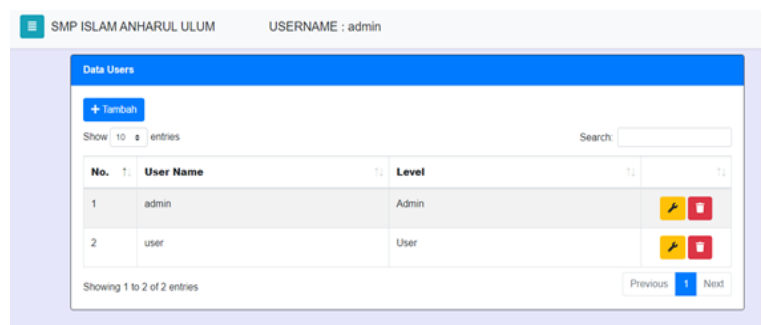

Gambar 11. Halaman Menu User

\subsection{Menu Report Perangkingan}

Menu ini dapat digunakan admin dan user untuk menampilkan Laporan Perangkingan nilai karakter siswa dengan cara memilih Kelas dan Semester yang diinginkan admin

SMP ISLAM ANHARUL ULUM USERNAME : admin

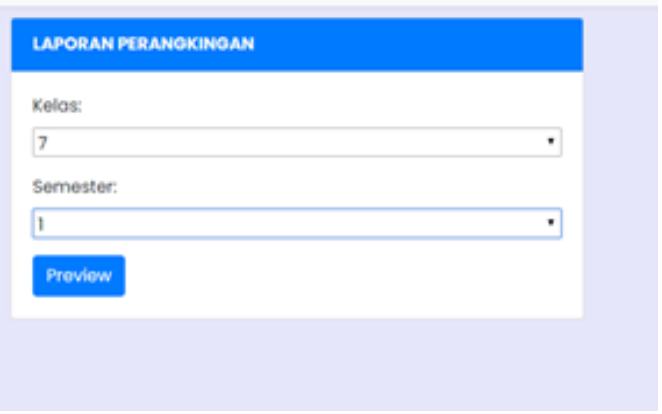

Gambar 12. Halaman Menu Siswa

Ketika klik tombol Preview akan muncul Laporan Perangkingan dalam bentuk file Pdf seperti gambar berikut.

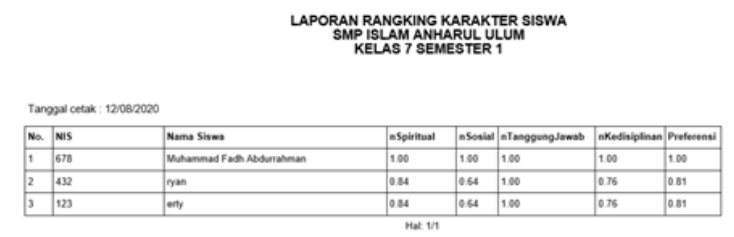

Gambar 13. Laporan Perangkingan

\subsection{Hasil Pengujian}

Dalam menentukan hasil pengujian memerlukan beberapa rencana pengujian, yang meliputi:

\section{1) Pengujian Alpha}

Sebuah aplikasi dapat diterapkan di sebuah instansi, harus memilki ketentuan aplikasi yang bebas dari kesalahan-kesalahan atau error dalam fungsionalitas kinerjanya. Oleh karena itu, aplikasi harus diuji coba terlebih dahulu agar dapat menemukan kesalahan-kesalahan yang mungkin terjadi, supayadapat diperaiki kembali jika terlalu banyak kesalahan yangmuncul. Seperti tabel berikut.

\section{a. Pengujian Login}

\section{Login Sebagai Admin}

Tabel 3. Pegujian Login Admin Kasus dan hasil uji (data normal)

\begin{tabular}{|c|c|c|c|}
\hline \multicolumn{4}{|c|}{ Kasus dan hasil uji (data normal) } \\
\hline $\begin{array}{c}\text { Data } \\
\text { masukan }\end{array}$ & $\begin{array}{c}\text { Yang } \\
\text { diharapkan }\end{array}$ & Pengamatan & Kesimpulan \\
\hline $\begin{array}{l}\text { User } \\
\text { Name } \\
\text { admin } \\
\text { Password } \\
: \\
\text { admin123 }\end{array}$ & $\begin{array}{l}\text { Muncul } \\
\text { halaman } \\
\text { utama } \\
\text { admin }\end{array}$ & $\begin{array}{l}\text { Muncul } \\
\text { halaman } \\
\text { utama } \\
\text { admin }\end{array}$ & Diterima \\
\hline \multicolumn{4}{|c|}{ Kasus dan hasil uji (data tidak normal) } \\
\hline $\begin{array}{c}\text { Data } \\
\text { masukan }\end{array}$ & $\begin{array}{c}\text { Yang } \\
\text { diharapkan }\end{array}$ & Pengamatan & Kesimpulan \\
\hline $\begin{array}{l}\text { Data } \\
\text { kosong }\end{array}$ & $\begin{array}{l}\text { Muncul } \\
\text { pesan } \\
\text { "Please fill } \\
\text { out this } \\
\text { field" }\end{array}$ & $\begin{array}{l}\text { Muncul } \\
\text { pesan } \\
\text { "Please fill } \\
\text { out this } \\
\text { field" }\end{array}$ & Diterima \\
\hline $\begin{array}{l}\text { User } \\
\text { Name } \\
\text { admaja } \\
\text { Password } \\
: \text { 123adm }\end{array}$ & $\begin{array}{l}\text { Muncul } \\
\text { pesan } \\
\text { login gagal }\end{array}$ & $\begin{array}{l}\text { Hasil sesuai } \\
\text { yang } \\
\text { diharapkan }\end{array}$ & Diterima \\
\hline
\end{tabular}

\section{Login Sebagai User}

Tabel 4. Pegujian Login User Kasus dan hasil uji (data normal)

\begin{tabular}{|c|c|c|c|}
\hline \multicolumn{4}{|c|}{ Kasus dan hasil uji (data normal) } \\
\hline $\begin{array}{c}\text { Data } \\
\text { masukan }\end{array}$ & $\begin{array}{c}\text { Yang } \\
\text { diharapkan }\end{array}$ & Pengamatan & Kesimpulan \\
\hline $\begin{array}{l}\text { User Name } \\
\text { : user } \\
\text { Password : } \\
\text { user }\end{array}$ & $\begin{array}{l}\text { Muncul } \\
\text { menu } \\
\text { utama } \\
\text { sesuai hak } \\
\text { akses user }\end{array}$ & $\begin{array}{l}\text { Muncul } \\
\text { menu } \\
\text { utama user }\end{array}$ & Diterima \\
\hline \multicolumn{4}{|c|}{ Kasus dan hasil uji (data tidak normal) } \\
\hline $\begin{array}{c}\text { Data } \\
\text { masukan }\end{array}$ & \begin{tabular}{|c|} 
Yang \\
diharapkan
\end{tabular} & Pengamatan & Kesimpulan \\
\hline $\begin{array}{l}\text { Data } \\
\text { kosong }\end{array}$ & $\begin{array}{l}\text { Muncul } \\
\text { pesan } \\
\text { "Please } \\
\text { fill out } \\
\text { this field" }\end{array}$ & $\begin{array}{l}\text { Muncul } \\
\text { pesan } \\
\text { "Please fill } \\
\text { out this } \\
\text { field" }\end{array}$ & Diterima \\
\hline $\begin{array}{l}\text { User Name } \\
\text { : guru } \\
\text { Password : } \\
\text { gr321 }\end{array}$ & $\begin{array}{l}\text { Muncul } \\
\text { pesan } \\
\text { login } \\
\text { gagal }\end{array}$ & $\begin{array}{l}\text { Hasil } \\
\text { sesuai yang } \\
\text { diharapkan }\end{array}$ & Diterima \\
\hline
\end{tabular}




\section{b. Pengujian Data Siswa}

\section{Tambah Data Siswa}

Tabel 5. Pegujian Tambah Data Siswa Kasus dan hasil uji (data normal)

\begin{tabular}{|c|c|c|c|}
\hline \multicolumn{4}{|c|}{ Kasus dan hasil uji (data normal) } \\
\hline Data masukan & Yang diharapkan & Pengamatan & Kesimpulan \\
\hline $\begin{array}{l}\text { NIS : } 598 \\
\text { Nama Siswa : Hendra } \\
\text { Tempat Lahir : Blitar } \\
\text { Tanggal Lahir : } 12 / 03 / 2005 \\
\text { Alamat : Desa Ngaglik Kec } \\
\text { Sanankulon Blitar } \\
\text { Jenis Kelamin : L } \\
\text { No Telp : 081708776523 } \\
\text { Nama Orang Tua : Supri } \\
\text { Alamat Orang Tua : Desa } \\
\text { Ngaglik Kec Sanankulon Blitar } \\
\text { Pekerjaan Orang Tua : Tani } \\
\text { No Telp Orang Tua : } \\
\text { 085239007100 }\end{array}$ & $\begin{array}{l}\text { Data muncul dalam } \\
\text { tabel Data Siswa. }\end{array}$ & $\begin{array}{l}\text { Data tidak sepenuhnya } \\
\text { muncul dalam tabel } \\
\text { Data Siswa. }\end{array}$ & Diterima \\
\hline \multicolumn{4}{|c|}{ Kasus dan hasil uji (data tidak normal) } \\
\hline Data masukan & Yang diharapkan & Pengamatan & Kesimpulan \\
\hline $\begin{array}{l}\text { Contoh salah satu data diksongi } \\
\text { NIS : } 145 \\
\text { Nama Siswa : dimas } \\
\text { Tempat Lahir : Blitar } \\
\text { Tanggal Lahir : 02/03/2007 } \\
\text { Alamat : Desa Centong Kec } \\
\text { Sanankulon Blitar } \\
\text { Jenis Kelamin : L } \\
\text { No Telp : 082450987125 } \\
\text { Nama Orang Tua : (kosong) } \\
\text { Alamat Orang Tua : Desa } \\
\text { Centong Kec Sanankulon Blitar } \\
\text { Pekerjaan Orang Tua : } \\
\text { Wiraswasta Th Orang Tua : } \\
\text { No Telp O85890712402 }\end{array}$ & $\begin{array}{l}\text { Muncul pesan "Please } \\
\text { fill out this field" }\end{array}$ & $\begin{array}{l}\text { Muncul pesan "Please } \\
\text { fill out this field" }\end{array}$ & Diterima \\
\hline
\end{tabular}

Dari hasil pengujian alpha yang telah diuji memperoleh presentase penilaian sebesar 93.86\%, menunjukkan bahwa aplikasi yang dibangun sudah memenuhi persyaratan fungsional dan sudah diterima oleh pihak sekolah. Secara fungsional sistem yang telah dibangun ada beberapa hasil keluaran atau output yang diharapkan blum sesuai keinginan pihak sekolah.

\section{2) Pengujian Beta}

Hasil dari pengujian beta yang telah diuji yaitu dengan menghitung pilihan kategori jawaban dari kuesioner yang telah dibagikan dilapangan memperoleh presentase sebesar 79,68 \%, sehingga dapat kesimpulan bahwa aplikasi yang dibangun mudah digunakan dan memiliki tampilan yang cukup bagus dan menarik. Aplikasi tersebut Sudah sesuai tujuan, yaitu mudah digunakan (user friendly), bermanfaat, teks yang mudah dibaca, penataan yang tepat dan dapat mempermudah menyampaikan informasi penilaian karakter siswa kepada orang tua siswa.

\section{KESIMPULAN DAN SARAN}

\subsection{Kesimpulan}

Simpulan yang didapat dari hasil penelitian pada perancangan aplikasi yang dibangun, tentang "Sistem Informasi Penilaian Karakter Siswa Terbaik Berbasis Web Dengan Metode SAW di SMP Islam Anharul Ulum" adalah sebagai berikut.

1. Sistem informasi penilaian karakter siswa terbaik berbasis web di SMP Islam Anharul Ulum melalui tahapan analisis, desain dan implementasi yang dirancang dengan menggunakan database $M y S Q L$ dan bahasa pemrogaman PHP telah berhasil, sehingga sistem memudahkan pihak sekolah dalam menyampaikan informasi kepada orang tua siswa.

2. Pembuatan Sistem informasi penilaian karakter siswa terbaik berbasis web di SMP Islam 
Anharul Ulum memiliki hasil pengujian Alpha Testing dengan hasil 93,86\% dan Beta Testing dengan hasil 79,68\%, maka dapat disimpulkan bahwa program dapat bekerja sesuai dengan spesifikasi yang telah ditentukan dan sesuai keinginan pihak sekolah. Pengujian perhitungan metode SAW memiliki selisih 0,01 antara perhitungan manual dengan perhitungan aplikasi. Hasil itu dikatakan normal atau valid karena pada perhitungan manual nilainya belum dibulatkan, sedangkan perhitungan aplikasi nilainya sudah dibulatkan.

\subsection{Saran}

Dari simpulan dan keterbatasan aplikasi yang telah diketahui, peneliti memiliki saran untuk pengembang aplikasi di masa yang akan datang agar aplikasinya tidak ketinggalan zaman. Saran tersebut meliputi:

1. Perlu ditambahkan layout presensi siswa.
2. Penilaianya dilakukan dalam setiap bulan.

3. Perlu ditambahkan report nilai raport.

4. Data siswa perlu dikelompokkan sesuai kelasnya.

\section{DAFTAR PUSTAKA}

[1] Abdul Kadir. 2009. Membuat Aplikasi Web dengan PHP + Database MySQL. Yogyakarta: Andi.

[2] Haryanto, D. 2008. Pengembangan sistem informasi akademik mahasiswa berbasis teknologi WAP di jurusan pendidikan teknik elektro FT UNY. Jurnal Pendidikan Teknologi dan Kejuruan, 139-166.

[3] Kusumadewi, S. Hatati, S. Harjoko, A. dan Wardoyo, R. 2006. Fuzzy Multi Attribute Decision Making (FUZZY MADM). Yogyakart: Graha Ilmu.

[4] Supriyanto Aji. 2005. Pengantar Teknologi Informasi. Jakarta: Salemba Infotek. 